\title{
Hiding Information in Open Auctions with Jump Bids*
}

\author{
David Ettinger and Fabio Michelucci
}

\begin{abstract}
We analyse a rationale for hiding information in open ascending auction formats. We focus on the incentives for a bidder to call a price higher than the highest standing one in order to prevent the remaining active bidders from aggregating more accurate information by observing the exact drop out values of the opponents who exit the auction. We show that the decision whether to allow jump bids or not can have a drastic impact on revenue and efficiency.
\end{abstract}

Economists have focused extensive attention on market environments where the aggregation of new information is important. ${ }^{1}$ The possibility of aggregating new information is also the key feature of open auction formats, which often leads auction theorists and designers to advocate the use of open auction formats as opposed to sealed bid auction formats.

The existing literature ignores the possibility that bidders in an auction might have an incentive to manipulate the quality (precision) of the new information that can be aggregated. We show that jump bids can be used to achieve this objective. In this paper, the information that bidders can manipulate is who is active and who is not at any given price. ${ }^{2}$ Under the standard modeling of the open ascending auction, when a bidder drops out his/her exact signal is pinned down by the remaining active bidders in equilibrium. However, when a jump bid is not matched by some of the bidders, the remaining active bidders can aggregate only coarser information of the private information of the bidders who did not match the jump bid. That is, a bidder may call a price in order to alter the information revelation process.

* Corresponding author: Fabio Michelucci, CERGE-EI, P.O. Box 882 Politickych veznu 711121 Praha 1 Czech Republic. Email: fabio.michelucci@cerge-ei.cz. CERGE-EI, a joint workplace of Charles University and the Economics Institute of the Academy of Sciences of the Czech Republic, Politickych veznu 7, 11121 Prague, Czech Republic.

We would like to thank Levent Çelik, Françoise Forges, Philippe Jehiel, Marco Pagnozzi, Margaret Meyer, Jakub Steiner and the participants in the Transatlantic Theory Workshop, PET, RES, ISNIE, Dauphine, Naples, Salerno, Lille, Caen, ASSET 2013, ESEM 2014, EARIE 2014, seminars for helpful discussions and feedback on earlier drafts of this paper. Finally, the current version has benefited from excellent comments from three anonymous referees, the editor in charge, and an associate editor. David Ettinger thanks the Governance and Regulation Chair for its support.

${ }^{1}$ See the literature on information aggregation, information disclosure, efficient auctions.

${ }^{2}$ In an interdependent value setting, this information affects bidders' expected valuations for the object and thus determines their bidding behaviour. 
This way of manipulating information aggregation is relevant, as in practice most open auction formats allow bidders (or the auctioneer) to call a price higher than the highest standing price and bidders do make use of this option. It is a well documented fact that jump bids are quite prevalent in several auction contexts, including, among others, many FCC auctions (see, for instance, Cramton (1997), Plott and Salmon (2004), Börgers and Dustmann (2005), Mark, Salmon, and Zillante (2007)), and online auctions (see, for instance, Easley and Tenorio (2004),Grether, Porter, and Shum (2012), He and Popkowski Leszczyc (2013)). Furthermore, jump bidding is prevalent in important markets, which are perhaps not always explicitly regulated by auction rules such as corporate takeovers. In finance, a voluminous literature has tried to explain the existence of high initial offers (jump bids) leading to a takeover premium (see Burkart and Panunzi (2008) for a review).

The main available theoretical justifications for the observed use of jump bids are based on a signaling motivation. ${ }^{3}$ Conceptually, the key difference between any explanation based on signaling and the one we propose is the following. In the former, the jump bid is meant to convey, early on in the auction, finer information about the private information of the bidder calling a price. In the latter, a jump bid is used to preclude opponents from aggregating finer information. We wish to provide an alternative theoretical explanation for jump bidding that could complement the existing ones, and might further guide the empirical investigations that test for jump bidding in auction markets, and corporate takeovers. Under our explanation, preventing more precise information is profitable, because the information would have a larger impact on the expected value of the strongest of the opponents rather than on the value of the bidder who jump bids. In practice, this could be the case if: 1) The object for sale is hard to evaluate; 2) The bidder who jump bids is an experienced bidder (thus less influenceable by the information held by other bidders); and 3) Some of the remaining bidders are more novice and strongly react to the information conveyed by the presence of one or more experienced bidders being active at high prices.

In the paper we provide possibility results via the use of different examples in specific auction frameworks. The examples differ in the exact nature of the asymmetry between players and the interdependence of payoffs. Our first example appears in Section 4, and it illustrates that a direct consequence of the foreclosure of finer information through a jump bid may be a decrease in the expected price paid by the bidder who jump bids, and consequently a decrease in revenues for the seller. It also shows that jump bidding may distort the equilibrium allocation in an inefficient way.

However, this is not the end of the story as the indirect effects of allowing jump bidding cannot be neglected. Such effects are present in the more strategically rich environments that arise when more than one bidder has an incentive to foreclose information. We analyse this possibility in Section

\footnotetext{
${ }^{3}$ We comment with more details in the next section. Other advanced explanations include bidders' impatience, bidding costs, and irrationality.
} 
5 using a series of specific examples that illustrate what we believe are the main strategic effects at play in the complex dynamic game that is generated when one allows for jump bids. In particular, we are able to provide the following additional insights: 1) When a jump bid is placed to prevent another bidder from placing another jump bid later in the auction, the ultimate effect of allowing for jump bids might be that all bidders are at least weakly worse off than in an open ascending auction where jump bids are banned (set-up 2); 2) It is possible that although jump bids are not observed in equilibrium, the fact they are allowed drastically changes the equilibrium outcome (set-up 3); 3) Allowing for jumps bids can increase both revenue and efficiency in environments where an instance of the free-rider problem prevents the aggregation of information during the auction (set-up 4). This last point is particularly interesting as jump bidding is found to dampen competition and lower revenue by the existing theoretical literature. Considering the widespread observation of jump bids in open auctions, this is believed to open to a puzzle as to why jump bidding is allowed. Our observation that jump bidding may rise expected revenue could provide an answer.

\section{Related Literature}

Within the works that use signaling models to explain jump bidding, we can distinguish some that follow a preemptive motivation, and others that follow a pure signaling motivation.

The first contribution suggesting the preemptive motivation for jump bidding is Fishman (1988). Other related works include Hirshleifer and Png (1989), Bhattacharyya (1992), Bernhardt and Scoones (1993). Fishman (1988) presents a two-bidders independent private value model in which one of the two bidders has an informational advantage: she is able to discover her valuation prior to the start of the auction while the other bidder cannot. ${ }^{4}$ If the first bidder's value is above some critical threshold, a jump bid that pre-empts the second bidder from investing and competing is placed. In this setting, a jump bid has an anti-competitive effect and reduces the seller's revenue. Bulow and Klemperer (2009) also use an independent private value model with entry costs but focus on the comparison between a simultaneous auction and a sequential sale mechanism in which a new entrant can place a jump bid to deter further participation. Generally, in their framework, sellers prefer the simultaneous auction (without jump bids) even though it is less efficient because of the higher entry costs involved. Interestingly, Roberts and Sweeting (2013) show that if potential entrants receive an informative signal prior to the entry decision and if they may be ex-ante asymmetric, the jump bidding equilibrium of the sequential sale mechanism may induce higher revenues and efficiency than the simultaneous auction. This is because their equilibrium is separating and potential entrants with higher expected values are

\footnotetext{
${ }^{4}$ Throughout the paper we use the convention to refer to the bidder who places a jump bid along the equilibrium path (in the game that allows jump bids) as "she", and to all the other bidders as "he".
} 
less deterred by jump bids.

The other leading justification for jump bidding was first proposed by Avery (1998). Using a symmetric model with affiliated valuations, he shows that jump bidding can be employed to select the strongest bidder during the first stage. During this stage, strong bidders signal that their type is high by placing a jump bid. The signaling induces asymmetric bidding behaviour in the second stage of the game with a strong bidder committing to a more aggressive strategy than a weak bidder. Such equilibrium behaviour can be viewed, as Avery points out, as a form of implicit collusion (it requires that the weaker bidder quits strictly below his expected value conditional on the informational content of the jump bid). More recently, Hörner and Sahuguet (2007) follow a similar approach, but they consider the use of a sealed bid format in the second stage (a First Price All Pay auction), and a pure private value structure. They show that an equilibrium exists in which signaling is not monotonic in the type.

Our setting differs in several dimensions from the ones mentioned above. For instance, we do not assume the existence of bidding costs or the successful implementation of an implicitly collusive strategy. The effect of a jump bid that we stress is the foreclosure of access to finer information. ${ }^{5}$ There is also some information foreclosure in Fishman (1988), but in his model the bidder who observes a jump bid can still acquire the finer information, even if, in equilibrium, he will not. In our model, the finer information is simply no longer available. Even though there is no cost of acquiring information in our setting, in an open ascending auction, the winner might experience a loss when winning. A bidder stays active at a price at which he would make a loss if he were to win because such loss is more than compensated by the potential profits of winning at a higher price, later in the auction. In other words, the bidder is active at lower prices in the hope of aggregating favorable information later on. Thus, one can view the mentioned expected losses as the implicit cost of aggregating information. ${ }^{6} \mathrm{It}$ is in this environment that we show that allowing jump bids can increase both revenue and efficiency. An efficiency improvement effect of limiting the amount of information disclosed in open ascending auctions is also found in Hernando-Veciana and Michelucci (2013). However, it is not due to the free riding phenomenon, that we illustrate here, and the improvement is achieved by switching to a different mechanism rather than by allowing jump bids.

Compte and Jehiel (2004) and Compte and Jehiel (2007) also point out that bidders might be active in an open auction in order to aggregate new information. The difference is that in those two papers the acquired information is exogenous.

Empirical evidence on the effect of jump bids is not vast, and only a few studies have tried to test the signaling explanation for jump bids. That said, the support for a signaling explanation to jump

\footnotetext{
${ }^{5}$ We are aware of only one other paper, Kirkegaard (2006), that proposes that jump bids might be used to conceal information. However, there, bidders do so in response to the auctioneer using phantom bids.

${ }^{6}$ See Hernando-Veciana and Michelucci (2011) for relevant economic applications where this applies.
} 
bidding seems inconclusive. For instance, within the literature on takeovers Dimopoulos and Sacchetto (2013) compare the signaling/preempting explanation against a target resistance explanation, and they find support for the latter. Betton and Eckbo (2000) find that jump bids are not limited to initial bids, and a similar observation can be made for FCC auctions (Mark, Salmon, and Zillante (2007)) and online auctions (He and Popkowski Leszczyc (2013)). Finally, Grether, Porter, and Shum (2012)'s evidence on auctions of used cars points out at an ambiguous effect on revenue. Our first set-up illustrates that jump bids can happen at different points in the auction. Our last set-up shows that jump bids can also raise revenue. Overall, our alternative explanation might provide an input for additional empirical testing.

The remainder of the paper is organized as follows. Section 2 introduces the model. Section 3 presents a natural environment where a jump bid emerges in equilibrium. Section 4 studies environments that are strategically more complex, illustrates some properties of jump bids, and shows that there is no clear-cut effect of jump bids on revenue and efficiency. Section 5 concludes.

\section{Auction setting}

We analyse a slightly modified version of the Japanese Auction (JA), which aims to capture an element of the dynamic features of the English Auction (EA) that cannot be represented when adopting the standard JA format, the opportunity to call a price.

\subsection{Environment}

A set $N$ of $i: 1, \ldots, n$ bidders is present at the start of the auction. No further entry takes place after the auction has started, and a decision to exit the auction is irreversible. Bidder $i$ 's private information is represented by a unidimensional signal $t_{i} \in T_{i}$, while the vector $t_{-i} \in T_{-i}$ contains the $n-1$ signals of i's opponents. Bidders' valuations are interdependent, i.e., $v_{i}\left(t_{i}, t_{-i}\right)$, with $v_{i}$ weakly increasing in $t_{j}$ for all arguments. We also assume quasi-linear utility so that $u_{i}\left(t_{i}, t_{-i}\right)=v_{i}\left(t_{i}, t_{-i}\right)-p$ if the bidder $i$ gets the object and pays price $p$, and $u_{i}\left(t_{i}, t_{-i}\right)=0$, if bidder $i$ does not get the object and no payment is required.

While $t_{i}$ is private to bidder $i$, the value functions $v_{i}$ as well as the cumulative distribution functions, $F_{i}$, from which the signals $t_{i}$ are independently drawn ${ }^{7}$ are common knowledge among bidders. In some of the following analysis we assume a discrete type space. We find this more convenient to illustrate our point, but it should be apparent that an environment with a continuous type space can always be constructed to derive the same insights.

\footnotetext{
${ }^{7}$ Except in some specific cases that we will describe.
} 


\subsection{Auction Rules}

We consider two versions of the Japanese auction. The standard Japanese auction without jump bids, which we call the $C$ game $^{8}$ and the $J$ game, a Japanese auction in which jump bids are allowed. The latter is defined as follows.

The price starts from a very low value, which we normalize to zero, and it is increased at a constant pace by an exogenous device such as a clock. Bidders are considered active only if they are currently pressing a button. At any point in time, i.e., at any price $p \geq 0$ indicated by the clock at a specific instant of time, each bidder faces a decision with three alternatives: exit at $p$ by releasing the button, remain active by keeping their hands on the button or, finally, call a price. The identity of the bidders who quit is publicly revealed so that a bidder knows exactly against whom he is competing at any time during the auction.

Using the third option, a bidder can interrupt the exogenous price increase. We assume that any jump bid offer must exceed the current price by a minimum increment $\varepsilon>0$ arbitrarily small. ${ }^{9}$ The clock is then stopped at the price indicated at that time and the price that has been called is publicly revealed. In case that more than one bidder simultaneously stops the clock, the right to call the price is assigned randomly by the auctioneer to one of the bidders who proposed the highest called price. ${ }^{10}$ At this point any bidder who was active when the clock was stopped can react and decide to call a higher price (exceeding the current price called by a minimum increment $\varepsilon>0$ arbitrarily small). The process is iterated until no bidder wants to raise the price called further. ${ }^{11}$ Then, the identity of the bidder who called the highest jump bid is publicly revealed, and all the bidders who were active independently decide whether they want to be active at the price being called. Then, the identities of the bidders who do not match the jump bid are publicly revealed.

The auction ends either when a price is called and no other bidder matches it or when, in the continuous price increase phase, the penultimate bidder quits. In the first case, the winning bid is given by the price that was called, in the second, by the price at which the penultimate bidder exited. We use the following tie-breaking rule. If the $k$ last active bidders (with $k \geq 2$ ) leave the auction at the same price, $p$, the good is sold at price $p$ with a probability $1 / k$ to each of the $k$ last active bidders.

The solution concept adopted is Perfect Bayesian Equilibrium (PBE). In order to rule out less interesting equilibria, we also assume that bidders do not play weakly dominated strategies.

\footnotetext{
${ }^{8}$ The price continuously increases.

${ }^{9}$ With this $\varepsilon$, we avoid the possibility of infinite (but converging) sequences of jump bids.

${ }^{10}$ The fact that other bidders also had stopped the clock is not revealed nor are the bidders' identities.

${ }^{11}$ An alternative rule could prohibit bidders from further raising the price before the identity of those who do not want to match the first jump bid is observed. Such alternative formulation would, in some part, make the analysis more cumbersome by adding an extra channel for bidders to interfere in each others optimal jump bidding strategy.
} 


\section{Information Aggregation and Jump Bids}

This section presents a natural set-up where a jump bid emerges in equilibrium and for which the rationale behind jump bidding is simple to understand from a strategic viewpoint.

We model an auction framework in which one bidder might benefit more than others from aggregating new information during the auction. A jump bid can be used to prevent this bidder from acquiring the finest information.

A piece of land is for sale. Bidder 1 and Bidder 2 are local actors, they know the characteristics of this piece of land for the type of production they are respectively interested in. Let us say, for instance, that Bidder 1 (call it Robinson) would like to produce coconuts and Bidder 2 (call it Friday) would like to produce whisky. Bidder 3 is also interested in buying the piece of land in order to produce whisky and export it. He does not know the value of the piece of land and he has access to a wider market that is further away so that he would incur a transportation cost. We represent this situation with the following framework.

\section{SET-UP 1.}

- For $i: 1,2, v_{i}=t_{i}$ with $F_{i}$ uniform on $[0,1]$ and $F_{1}$ and $F_{2}$ independent.

- $v_{3}=\beta t_{2}-\alpha$ with $\alpha>0$ and $6 \alpha \geq \beta \geq 2 \alpha+1$.

Before analyzing this set-up, we define $p^{*}$ with the following equation: $p^{*}=\beta p^{*}-\alpha \cdot p^{*} \in(0,1)$ and it is unique since $\alpha>0$ and $\beta \geq 2 \alpha+1$. If $t_{2}<p^{*}, v_{2}\left(t_{2}\right)>v_{3}\left(t_{2}\right)$, if $t_{2}>p^{*}, v_{2}\left(t_{2}\right)<v_{3}\left(t_{2}\right)$ and if $t_{2}=p^{*}, v_{2}\left(t_{2}\right)=v_{3}\left(t_{2}\right) \cdot p^{*}$ is the value of $t_{2}$ for which bidder 2 and bidder 3's valuations cross. This is coherent with our story. The foreigner cares more about the value of the piece of land than Friday but he faces a fixed cost. The linearity of the value function, and the use of uniform distributions only help the presentation but are not crucial for the arguments. For the same reason, we do not endow Bidder 3 with any private information. The slopes of Bidder 1 and Bidder 2's values being set equal to 1 and the intercepts to 0 are only a normalization. What is crucial is that the values of Bidder 2 and Bidder 3 cross, and that the two slopes differ enough, which is guaranteed by the above conditions on $\alpha$ and $\beta .{ }^{12}$ The fact that the slopes need to differ enough is natural for the type of environment we want to model. The key element is that one (or more) bidder(s) can become substantially more competitive relative to the others if they aggregate some specific information during the auction. For more examples where this might be relevant, see section 7.1 in Ettinger and Michelucci (2012).

Now let us begin with the $C$ game, where jump bids are not allowed. Since bidders do not play weekly dominated strategies, in any considered equilibrium of the $C$ game, Bidder 1 and Bidder 2

\footnotetext{
${ }^{12}$ We could make assumptions less restrictive than these and derive equilibrium jump bids but these ease our exposition.
} 
leave the auction when the price reaches their respective valuations for the good, which is their unique weakly dominant strategy. In contrast, Bidder 3 does not know his valuation for the good at the beginning of the auction. As long as Bidder 1 and Bidder 2 are still active, it is not costly for Bidder 3 to wait and see, since the probability that both bidders will leave exactly at the same price is equal to zero. If Bidder 2 leaves first, Bidder 3 can compute his expected valuation conditional on this observation and stay active up to this price or leave immediately. The real issue for Bidder 3 is what to do when Bidder 1 leaves first for a price strictly lower than $p^{*}$. In that case, it is not obvious that he should decide to stay active and learn finer information about the value of the good by observing Bidder 2's bidding behaviour. If he does so, Bidder 3 incurs a loss equal to $\alpha+(1-\beta) p$ when Bidder 2 leaves for a price $p$ strictly lower than $p^{*}$. Thus, he stays active only if his potential gain compensates for this type of loss. This is the case. The condition $\beta>2 \alpha+1$ guarantees that even if Bidder 1 leaves the auction immediately, the expected profit of Bidder 3, if he stays active up to 1 , is positive. These elements are summarized in the following result.

RESULT 1. In any equilibrium of the $C$ game: Bidder 1 and Bidder 2 leave the auction when the price reaches their respective valuations for the good. With probability 1, Bidder 3 stays active until Bidder 2 leaves the auction. If Bidder 2 leaves the auction at price $p \leq p^{*}$, Bidder 3 leaves immediately after Bidder 2, and if Bidder 2 leaves the auction at price $p>p^{*}$, Bidder 3 stays active up to $\beta p-\alpha$.

Now, let us consider the $J$ game. There is only one bidder, Bidder 1, who has an incentive to jump bid, and we assume that he places at most one jump bid (see the proof in the Appendix). Therefore, we can refer to a jump bid simply as $\left(p_{1}, p_{2}\right)$, where $p_{1}$ is the price at which the clock is stopped and $p_{2}$ the price called.

The key element of the environment we present is that Bidder 1 would prefer Bidder 3 not to discover the value of $t_{2}$ by observing at which price Bidder 2 leaves the auction, since Bidder 3 may become a strong opponent. By placing a jump bid $\left(p_{1}, p_{2}\right)$, Bidder 1 may manage to alter this revelation process. If Bidder 2 is active before the jump bid and does not choose to follow the jump bid, Bidder 3 can only assume that $t_{2} \in\left[p_{1}, p_{2}\right]$. Therefore, he will stay active up to $\max \left(p_{2}, \beta \frac{p_{1}+p_{2}}{2}-\alpha\right)$. Such a jump bid can be profitable for Bidder 1 if $E\left[\max \left(v_{2}, v_{3}\right) \mid t_{2} \in\left[p_{1}, p_{2}\right]\right]>\max \left(p_{2}, \beta \frac{p_{1}+p_{2}}{2}-\alpha\right)$. We will see that values of $\left(p_{1}, p_{2}\right)$ exist such that this is the case. This observation is formalized in the following result.

RESULT 2. An equilibrium of the $J$ game exists with the following properties.

- Bidder 1. If $t_{1} \leq p^{*}$, she stays active until the auction reaches $t_{1}$, leaves at that price and never calls a price. If $t_{1}>p^{*}$, she stays active until the auction reaches $p_{1}=\frac{-4 \alpha+6 \alpha \beta+2 \beta t_{1}-\beta^{2} t_{1}}{4-8 \beta+5 \beta^{2}}<p^{*}$, calls $p_{2}=\frac{4 \alpha(\beta-1)+\beta^{2} t_{1}}{4-8 \beta+5 \beta^{2}}>p^{*}$ at $p_{1}$ and then stays active up to $t_{1}$ without calling a price. 
- Bidder 2 stays active until the auction reaches $t_{2}$, leaves at that price or when a price higher than $t_{2}$ is called and never calls a price.

- Bidder 3. As long as no price is called, he stays active as long as Bidder 2 does also. If Bidder 2 leaves when the price is lower than $p^{*}$, Bidder 3 immediately leaves. If Bidder 2 leaves at a price $p>p^{*}$, he stays active up to $\beta p-\alpha$. If Bidder 1 places a jump bid $\left(p_{1}, p_{2}\right)$, when Bidder 2 is still active at $p_{1}$, Bidder 3 follows the jump bid. If Bidder 2 also does, Bidder 3 stays active as long as Bidder 2 does so and then stays active up to $\beta p-\alpha, p$ being the price at which Bidder 2 leaves the auction. If Bidder 2 does not follow the jump bid, Bidder 3 leaves when the auction reaches $\max \left(p_{2}, \beta \frac{p_{1}+p_{2}}{2}-\alpha\right)$.

Proof. See the Appendix

The intuition of this equilibrium is as follows. Bidder 2 cannot use a jump bid in order to profitably hide information from Bidder 3, since he would always call a price lower than his valuation and Bidder 3 would always stay active after the jump bid. Therefore, he sticks to a simple strategy: always to stay active when the price is lower than his valuation for the good. Bidder 3's behaviour also has the flavour of a standard best response to the behaviours of the other two bidders. He has no information to hide or to signal. Notice that, in the proposed equilibrium, Bidder 3 always matches a jump bid regardless of his characteristics. This is not costly since, in equilibrium, Bidder 1 has a strictly higher value than $p_{2}$ and remains active after the jump bid.

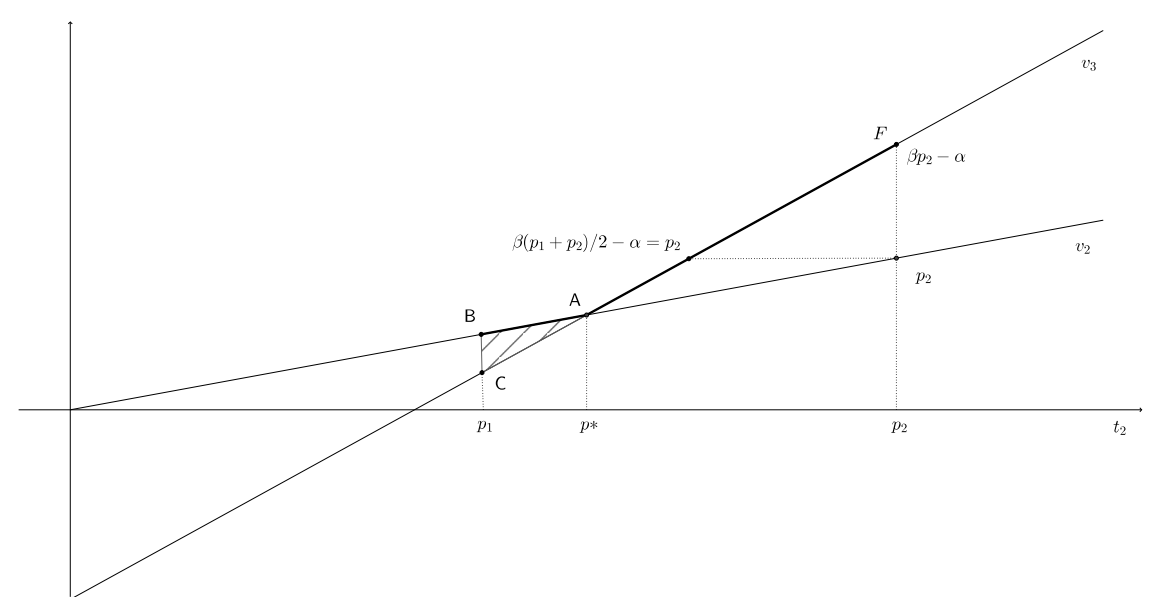

Figure 1: Example with $\beta=3, \alpha=1,\left(p_{1}, p_{2}\right)=(0.4,0.8), v_{3}\left(\left(p_{1}+p_{2}\right) / 2\right)=v_{2}\left(p_{2}\right)=p_{2}$ 
Now, let us focus on Bidder 1's behaviour. As we mentioned earlier, Bidder 1 may try to hide information from Bidder 3 with a jump bid $\left(p_{1}, p_{2}\right)$. The jump bid is directly profitable if and only if $E\left[\max \left(v_{2}, v_{3}\right) \mid t_{2} \in\left[p_{1}, p_{2}\right]\right]>\max \left(p_{2}, \beta\left(\frac{p_{1}+p_{2}}{2}\right)-\alpha\right)$. For this condition to be satisfied, we must have $p_{2}>p^{*}$ otherwise $E\left[\max \left(v_{2}, v_{3}\right) \mid t_{2} \in\left[p_{1}, p_{2}\right]\right]=E\left[v_{2} \mid t_{2} \in\left[p_{1}, p_{2}\right]\right] \leq \max \left(p_{2}, \beta\left(\frac{p_{1}+p_{2}}{2}\right)-\alpha\right)$ and $p_{1}<p^{*}$ otherwise $E\left[\max \left(v_{2}, v_{3}\right) \mid t_{2} \in\left[p_{1}, p_{2}\right]\right]=E\left[\beta t_{2}-\alpha \mid t_{2} \in\left[p_{1}, p_{2}\right]\right] \leq \max \left(p_{2}, \beta\left(\frac{p_{1}+p_{2}}{2}\right)-\alpha\right)$. With her jump bid, Bidder 1 should mix cases in which Bidder 2 has the highest valuation and cases in which Bidder 3 has the highest valuation.

In order to better understand the extra profit that Bidder 1 derives from a jump bid, first let us focus on a jump bid that does not alter the allocation that one would have in the equilibrium of the $C$ game. This requires $t_{1}>\beta p_{2}-\alpha$, that is a high enough valuation of Bidder 1 relatively to the price called. Consider then a jump bid $\left(p_{1}, p_{2}\right)$ with $p_{1}<p^{*}<p_{2}$ such that $E\left[v_{3} \mid t_{2} \in\left[p_{1}, p_{2}\right]\right]=p_{2}$. The jump bid affects the outcome of the auction only when $t_{2} \in\left[p_{1}, p_{2}\right]$ (considering Bidder 2 and Bidder 3 's strategies). In that case, without the use of a jump bid, Bidder 1 would win the auction and her expected payment would be $E\left[\max \left(v_{2}, v_{3}\right) \mid t_{2} \in\left[p_{1}, p_{2}\right]\right]=\frac{p^{*}-p_{1}}{p_{2}-p_{1}}\left(\frac{p_{1}+p^{*}}{2}\right)+\frac{p_{2}-p^{*}}{p_{2}-p_{1}}\left(\beta\left(\frac{p^{*}+p_{2}}{2}\right)-\alpha\right)$, the average value of the bold segment of figure 1 . For the same values of $t_{2}$, suppose that Bidder 1 placed a jump bid $\left(p_{1}, p_{2}\right)$; she would then win the auction and pay $p_{2}=E\left[v_{3} \mid t_{2} \in\left[p_{1}, p_{2}\right]\right]$ (by construction), which is the average of segment $\mathrm{CF}$ on figure 1. Hence, on this graph the extra profit due to the jump bid is represented by the triangle ABC.

COROLLARY 1. In the equilibrium of the $J$ game stated in result 2, the equilibrium jump bid placed by Bidder $1,\left(p_{1}, p_{2}\right)$, is such that $p_{1}$ is decreasing in Bidder 1 's type, while $p_{2}$ is increasing in Bidder 1 's type.

The corollary above points out that jump bids can happen at different times during the auction process, and one should expect later jump bids to come from lower types bidders.

It might be intuitive that the higher a bidder's type the higher the jump bid placed, but perhaps less so why the higher a bidder's type, the earlier the jump. To see why note that with the jump bid, Bidder 1 mixes states of the world in which Bidder 2 holds a higher value than Bidder 3 with other states of the world in which the reverse holds. Placing a higher jump bid means to hide (potentially) more states of the world for which Bidder 3 would have the highest value, and this needs to be counterbalanced by adding states of the world for which Bidder 2 would have the highest value. Otherwise, the expected value of Bidder 3 (conditional on Bidder 2 not matching Bidder 1's jump bid) would increase too much.

Let us also remark that when Bidder 1 calls a price, she does not intend to send a message about her valuation for the good. Even though her jump bid perfectly reveals her private information, 
neither of the two other bidders care about that information. ${ }^{13}$

The following result shows that allowing for jump bids in set-up 1 has a negative impact on the efficiency attainable by the open ascending auction. ${ }^{14}$

RESULT 3. In the equilibrium of the $J$ game that we considered, the allocation is less efficient and the expected revenue is strictly lower than with the equilibrium of the $C$ game.

Proof. Regarding expected revenue, we obtain the result with simple computations. The jump bid only affects the outcome of the auction when $t_{1}>p^{*}$ and $t_{2} \in\left[p_{1}, p_{2}\right]$. In that case, in the $C$ game, the expected revenue is equal to:

$$
\frac{p^{*}-p_{1}}{p_{2}-p_{1}} \frac{p^{*}+p_{1}}{2}+\frac{\frac{t_{1}+\alpha}{\beta}-p^{*}}{p_{2}-p_{1}} \frac{t_{1}+p^{*}}{2}+\frac{p_{2}-\left(\frac{t_{1}+\alpha}{\beta}\right)}{p_{2}-p_{1}} t_{1}
$$

and in the $J$ game, it is equal to $p_{2}$. The difference between these two terms is equal to $\frac{(\beta-2)^{2}\left(\beta t_{1}-t_{1}-\alpha\right)}{4(\beta-1) \beta^{2}}$, which is strictly positive when $t_{1}>p^{*}$ with our assumptions. Hence, the result.

The allocations in the $C$ game and in the $J$ game only differ in cases when Bidder 1 calls a price. In the $J$ game, Bidder 1 calls a price when $t_{1}>p^{*}$. In this case, in the $C$ game, at the equilibrium, the auction is always efficient. In the $J$ game, if $t_{1}>p^{*}$ and $t_{2} \in\left(\frac{t_{1}+\alpha}{\beta}, p_{2}\right]$, Bidder 2 does not stay active after the jump bid and Bidder 3 also immediately leaves the auction after observing that Bidder 2 does not match the jump bid. Bidder 1 obtains the good although $v_{3}>v_{1}$ since $v_{3}>\beta \frac{t_{1}+\alpha}{\beta}-\alpha=t_{1}=v_{1}$. Therefore, the jump bid may reduce the efficiency of the auction. We also need to check that the interval $\left(\frac{t_{1}+\alpha}{\beta}, p_{2}\right]$ is not empty for some values of $t_{1}$. This is the case if $p_{2}-\frac{t_{1}+\alpha}{\beta} \geq 0 . p_{2}-\frac{t_{1}+\alpha}{\beta}=\frac{(\beta-2)^{2}\left(\beta t_{1}-t_{1}-\alpha\right)}{\beta\left(5 \beta^{2}-8 \beta+4\right)}$. This formula is increasing in $t_{1}$ and equal to 0 when $t_{1}=p^{*}$. Hence, the condition is satisfied.

In order to get an intuition of this negative effect of jump bids on efficiency, let us go back to figure 1. A measure of the profit due to the jump bid is the area of the triangle $A B C$. It is decreasing in $p_{1}$. Therefore, the lower $p_{1}$ (and the higher $p_{2}$ since we assume that $p_{2}=\frac{2 \alpha-\beta p_{1}}{\beta-2}$ ), the higher the profit. This is true since $t_{1} \geq \beta p_{2}-\alpha$ is equivalent to $p_{2} \leq \frac{t_{1}+\alpha}{\beta}$. In these cases, the jump bid does not modify the allocation. If bidder 1 calls a higher price $p_{2}$, she also pools together with her jump bid values of $t_{2}$ for which she would have lost the auction. This comes with a loss. However, when

\footnotetext{
${ }^{13}$ In fact, she can choose a jump bid that perfectly reveals her private information precisely because it is not costly to reveal that information.

${ }^{14}$ Other Perfect Bayesian Equilibria such that only jump bids that do not modify the equilibrium allocation of the $C$ game (as of the type used to illustrate the revenue result) might be obtained. However, that requires a less plausible choice of out of equilibrium beliefs, to rule out the use of the more profitable distortionary jump bids proposed in result 2 .
} 


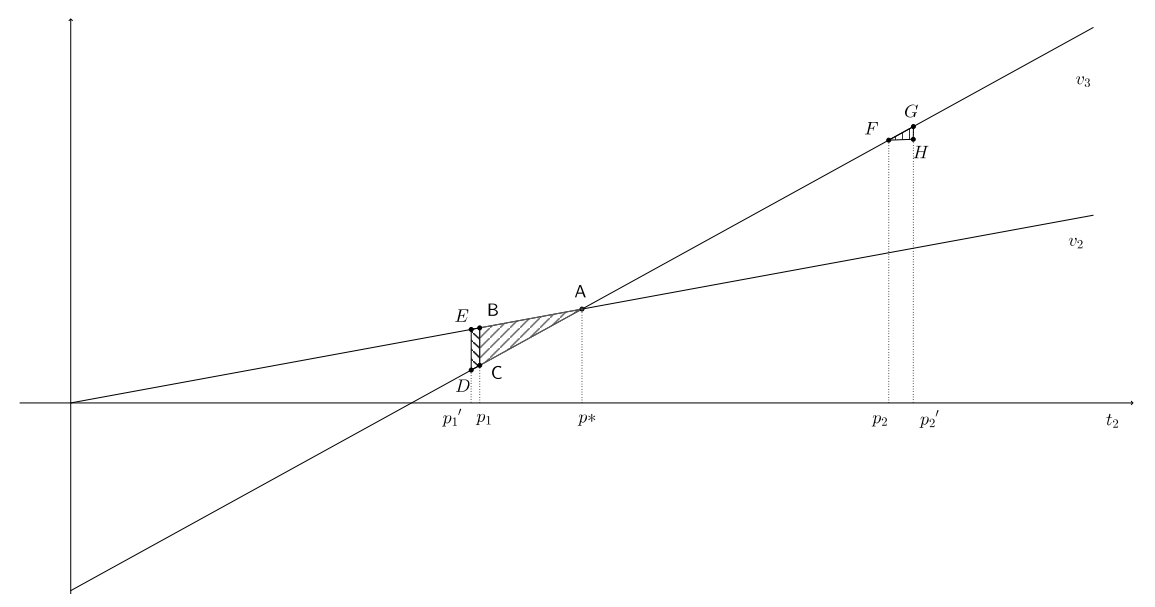

Figure 2: Example with $\beta=3, \alpha=1,\left(p_{1}^{\prime}, p_{2}^{\prime}\right)=(0.4-\epsilon, 0.8+3 \epsilon)$

the price is slightly higher than $\frac{t_{1}+\alpha}{\beta}$, this loss is much lower than the increase in profits (as shown in figure 2 in which the loss is represented by the area of the triangle $F G H$ and the extra profit the area of the trapeze $B C D E$ ) so that Bidder 1 calls a price strictly higher than $\frac{t_{1}+\alpha}{\beta}$. Therefore, the allocation is inefficient when a price is called and $t_{2} \in\left(\frac{t_{1}+\alpha}{\beta}, p_{2}\right]$.

We will see in the remainder paper that the negative effect on efficiency and revenue is not a general property of jump bids.

\section{Strategically More Complex Environments}

In this section, we consider strategically more complex environments in order to illustrate properties of jump bids. In particular, the set-ups that follow capture some dynamic features that were absent in the setting considered earlier, as there was only one bidder with the incentive to jump bid. We have selected specific set-ups to illustrate in the simplest possible way the most interesting effects that this extra complexity brings.

In the first subsection (set-up 2), we show that a bidder may be induced to jump bid by the anticipation of someone else hiding some information later on. Eventually, everybody may be strictly worse off in the $\mathrm{J}$ game than in $C$ game. This is interesting because it is generally thought that jump bids are anti-competitive and thus should be banned by the seller, but that bidders who place them are strictly better off when jump bids are allowed. Here, instead, the bidder who calls a price would be better off in the $C$ game. ${ }^{15}$

In the first example of the second subsection (set-up 3), we show that a bidder may be induced to

\footnotetext{
${ }^{15}$ Proposition 4 below illustrates a stronger result that even if one bidder was the only one allowed the option to jump bid, it is possible that she would be willing to pay to avoid having such an option.
} 
quit earlier than she would, if jump bids were not allowed. Interestingly, even though no jump bids are observed in equilibrium, the equilibrium outcome is drastically affected by the fact that bidders have such an option.

Finally, the second example of the second subsection (set-up 4) illustrates that there are instances in which the $\mathrm{C}$ game fails to aggregate new information, while, surprisingly, allowing for jump bids raises both revenue and efficiency.

\subsection{A Jump Bid to Prevent Another Jump Bid}

We consider a setting in which a bidder might be induced to jump bid by the anticipation that another bidder may strategically hide some relevant information (via a jump bid) later on. This, in turn, induces one of these two bidders to further anticipate her jump bid. The setting is therefore suggestive of the fact that the dynamic environment we study rapidly becomes extremely strategically complex once one departs from the set-ups of section 3 .

An interesting feature illustrated by this subsection is that all the bidders as well as the seller are worse off with the equilibrium of the $J$ game than with the equilibrium of the $C$ game. We consider the following setting:

\section{SET-UP 2.}

- $t_{1} \in\{8,9,10\}, p\left(t_{1}=8\right)=p\left(t_{1}=9\right)=p\left(t_{1}=10\right)$.

- $v_{1}\left(t_{1}\right)=t_{1}$

- $v_{2}\left(t_{1}=8\right)=8.5 ; v_{2}\left(t_{1}=9\right)=14 ; v_{2}\left(t_{1}=10\right)=16$

- $v_{3}\left(t_{1}=8\right)=0 ; v_{3}\left(t_{1}=9\right)=0 ; v_{3}\left(t_{1}=10\right)=20$

We begin with the analysis of the $C$ game. Any equilibrium of the $C$ game has the following properties. Bidder 1 knows the value of $v_{1}$ and therefore stays active till $v_{1}$ is reached. Bidder 2 exits at 8.5 if Bidder 1 exits at 8 , she exits at 14 if Bidder 1 exits at 9 and she exits at 16 if Bidder 1 exits at 10. Bidder 3 exits immediately if Bidder 1 exits at 8 or at 9 and he exits at 20 if Bidder 1 exits at 10. The expected revenue in the $C$ game is 11 .

Consider the effect of allowing jump bids in this setting. In order to choose their jump bidding strategy, bidders need to take into account that at any current price, if they let the price increase without calling a price, the other bidders might have an incentive to call a price later in the auction and modify the way the information is aggregated in their favor. In this case, the key element is that Bidder 2, once she discovers that $t_{1} \neq 8$, would like to prevent Bidder 3 from discovering whether $t_{1}$ is equal to 9 or to 10 . She can do so by calling a price 10 after having observed that Bidder 1 is 
still active at price 8 . In that case, Bidder 1 immediately leaves; Bidder 3's expected value for the good is also 10 (since he cannot distinguish between the two states $t_{1}=9$ and $t_{1}=10$ ), and therefore he also immediately leaves the auction. In this case, Bidder 3 always makes a zero profit. However, anticipating the unfolding of the game, Bidder 3 can do better by placing a jump bid from price 0 to 9 . In this case, if Bidder 1 immediately leaves, Bidder 2 has an expected value of $(8.5+14) / 2=45 / 4>9$. Thus, Bidder 2 stays active and Bidder 3 immediately leaves after having observed that Bidder 1 has left. Bidder 2 wins the auction at a price 9 and obtains $9 / 4$. Instead, if Bidder 1 stays active after the jump bid (and up to 10), Bidder 3 stays active up to 20 and Bidder 2 up to 16. This yields Bidder 3 an expected profit of $4 / 3$, making the jump bid profitable. However, this is not yet the equilibrium. In fact, anticipating Bidder 3 jump bid from 0 to 9 , Bidder 2 is better off placing a jump bid from 0 to 10 (recall that if the two jump bids are called at the same time, the highest is selected). In fact, this yields Bidder 2 expected profits of $17 / 6>9 / 4$.

RESULT 4. An equilibrium of the $J$ game exists in which Bidder 2 calls a price 10 at the beginning of the auction and no other bidder stays active after the jump bid.

In this equilibrium of the $J$ game, the expected revenue is 10, which is less than 11 under the $C$ game. Bidder 3 never wins under the $J$ game and therefore is strictly worse off. Bidder 1 never wins in either cases. Bidder 2 is also strictly worse off (in expectations) as her expected profits are 11/3 in the $\mathrm{C}$ game and $17 / 6$ in the $\mathrm{J}$ game.

All the bidders and the seller prefer the equilibrium outcome of the $C$ game. Thus, this equilibrium of the $J$ game is Pareto dominated by the equilibrium of the $\mathrm{C}$ game.

\subsection{Information Aggregation and Ex-Post Regret}

In the next two subsections, we focus on an environment where, in the $C$ game, some bidders might experience ex-post regret in equilibrium (see Hernando-Veciana and Michelucci (2011) for other relevant applications). ${ }^{16}$ Bidders accept to suffer from ex-post regret in equilibrium because the expected losses are more than compensated by the expected gains that follow from aggregating further information during the auction. Hernando-Veciana and Michelucci (2013) have shown that in such environments, the open ascending auction is prone to rushes, which are detrimental to efficiency. They also show that alternative mechanisms that limit the information that bidders can aggregate can increase efficiency. Here, we provide a novel, unrelated insight, that arises when bidders benefit in an asymmetric way from the aggregation of new information.

\footnotetext{
${ }^{16}$ Also in section 5.1 Bidder 3 is active at prices at which, conditional on winning, he would make a loss. However, such event does not arise in equilibrium.
} 
In particular, in the first subsection, in the $C$ game the private information that bidders hold is aggregated in a very desirable way thanks to the possibility of the wait and see strategy described in the introduction. In this case, allowing bidders to call a price causes both efficiency and revenue to drop. Conversely, in the next subsection, in the $C$ game the information fails to aggregate because the cost of staying active when other competitors are also active may lead to a free rider issue. This results in no bidder being willing to acquire finer information by staying active in the auction. In this latter case, the possibility of jump bidding allows the bidder with the ex-ante higher valuation to hide the piece of information causing such a free-rider issue. She may then profitably win the auction. This boosts both efficiency and revenue.

\subsubsection{The hidden impact of allowing jump bids}

We start with the scenario where the aggregation of information is very smooth in the $C$ game. This setting also illustrates that in the $J$ game, the anticipation of a future jump bid may induce a bidder to quit earlier than he would in the $\mathrm{C}$ game and that, even though no jump bid is observed in equilibrium, the equilibrium outcome in the $\mathrm{J}$ game substantially differs from the one in the $\mathrm{C}$ game.

\section{SET-UP 3.}

- $t_{1} \in\{5,6,7\}$ with $P\left(t_{1}=5\right)=P\left(t_{1}=6\right)=P\left(t_{1}=7\right)=\frac{1}{3}$.

- $v_{1}\left(t_{1}\right)=t_{1}$.

- $v_{2}\left(t_{1}=5\right)=0, v_{2}\left(t_{1}=6\right)=v_{2}\left(t_{1}=7\right)=9$.

- $v_{3}\left(t_{1}=5\right)=v_{3}\left(t_{1}=6\right)=0, v_{3}\left(t_{1}=7\right)=12$.

For both uninformed bidders, winning if $t_{1}=5$ entails a significant loss as they learn that $t_{1}=5$ when $p=5$ and both value the object at a price zero.

In the $\mathrm{C}$ game, the information is aggregated in a desirable way during the auction.

RESULT 5. In any equilibrium of the $C$ game, Bidder 1 stays active until his private value is reached. Bidder 2 quits as soon as Bidder 1 quits if that happens at a price lower than 5, and otherwise stays active until the price reaches 9 . Bidder 3 quits as soon as Bidder 1 quits if that happens at a price lower than 6 , and otherwise stays active until the price reaches 12 .

The $C$ game allows Bidder 2 and Bidder 3 to share the risk of winning when $t_{1}=5$, (the expected

loss being $\left(\frac{1}{3}\right)\left(\frac{1}{2}\right) 5=\frac{5}{6}$ for each). Furthermore, the two bidders can split the benefits of being active at higher prices in a way that allows both bidders to recover the expected losses. In the case $t_{1}=6$, 
Bidder 2 earns a profit of $9-6=3$; while if $t_{1}=7$, Bidder 3 earns a profit of $12-9=3$. The expected revenue is equal to $R^{C}=\left(\frac{1}{3}\right) 5+\left(\frac{1}{3}\right) 6+\left(\frac{1}{3}\right) 9=\frac{20}{3}$. The expected value of the winner is equal to $E^{C}=\left(\frac{1}{3}\right) 9+\left(\frac{1}{3}\right) 12=\frac{21}{3}=7$.

Now, if we allow jump bids, the smooth sharing of costs and benefits becomes unattainable and given that Bidders 2 and Bidder 3 can be active at low prices only if they do so jointly, they both quit early.

RESULT 6. In any equilibrium of the $J$ game, Bidder 1 stays active until the price reaches his private value, Bidder 2 and Bidder 3 leave the auction at a price lower than 5.

To understand why such behaviours arise at the equilibrium, note that as soon as the price rises just above 5 , Bidder 2 learns that $t_{1} \neq 5$ and thus that $v_{2}=9$. Conversely, at that price Bidder 3 is still uncertain regarding his exact value. Bidder 2 can hide such information from Bidder 3 by calling a price equal to 7 when the current price is still in $(5,6)$. The jump bid pulls together the two cases, $t_{1}=6$ and $t_{1}=7$, for Bidder 3 , who consequently bids up to $E\left(v_{3} \mid t_{1} \neq 5\right)=6$. With the jump bid, Bidder 2 makes a sure profit of 2 as opposed to winning only if $t_{1}=6$ if he lets the price increase continuously. The latter strategy yields $\frac{1}{2}(9-6)=\frac{3}{2}<2$; therefore, Bidder 2 cannot commit not to call such a price. Then, Bidder 3 anticipating that Bidder's 2 jump bid will pre-empt him from winning in the only profitable case, he is no longer willing to stay active over the price $p=5$. Since Bidder 3's presence is necessary for Bidder 2 (his expected gain with the jump bid strategy is $\frac{4}{3}$ but his expected loss if he does not share the risk is $\frac{5}{3}$ ), the equilibrium outcome is that they both quit the auction at a price lower than $5 .{ }^{17}$ This brings a revenue lower than 5 for any value of $t_{1}$, and it inefficiently always allocates the object to Bidder 1.

In such a context, if the seller is not aware of the implications of allowing bidders to call a price, he/she may be wrongly induced to believe that the bidders' valuations were low.

We report the main results of this subsection in the two propositions below.

PROPOSITION 1. An equilibrium of the $J$ game may exist whose allocation and revenue differ from the allocation and the revenue of any equilibrium of the $C$ game even though in this equilibrium of the $J$ game no price is ever called.

PROPOSITION 2. A bidder may accept to pay a strictly positive amount to the auctioneer for prohibiting him to call a price.

\footnotetext{
${ }^{17}$ Any other jump bid by Bidder 2 or Bidder 3 , it is also not profitable.
} 
Proof. Take the setting above. Suppose that Bidder 2 is the only bidder allowed to jump bid. Since in the $\mathrm{J}$ game he never wins, he would be willing to pay up to his expected profits in the $\mathrm{C}$ game to restrict his strategies space to the choice of quitting or staying active.

\subsubsection{A free-rider problem and the existence of efficiency and revenue enhancing jump bids}

In this setting, we show that in the $\mathrm{C}$ game, perverse incentives may impede the aggregation of information and that the enlarged strategy set of the $\mathrm{J}$ game may alleviate such a problem and bring higher revenue and efficiency.

\section{SET-UP 4.}

- $t_{1} \in\{9,10\}, \operatorname{Pr}\left(t_{1}=9\right)=\operatorname{Pr}\left(t_{1}=10\right)=\frac{1}{2}$.

- $v_{1}=t_{1}$.

- $v_{2}\left(t_{1}=9\right)=8, v_{2}\left(t_{1}=10\right)=13$.

- $v_{3}\left(t_{1}=9\right)=0, v_{3}\left(t_{1}=10\right)=18$.

The setting is similar to the previous one in so far as both Bidder 2 and Bidder 3 may have an incentive to wait and see. However, here one of them, Bidder 2, has an ex-ante value strictly higher than Bidder 1's. This means that if Bidder 2 were the only bidder competing with Bidder 1, she would profitably be active over the price of 9 to be able to discover the value of $t_{1}$. Bidder 3 could potentially benefit from the active presence of Bidder 2 over the price of 9 . However, if both bidders are active at that price, they share the expected losses but not the expected gains. In fact, if Bidder 3 infers that $t_{1}=10$, he always wins against Bidder 2 . However then Bidder 2 prefers to stay active only until the price is 8 to avoid incurring a loss. In turn, if that is the case, Bidder 3 also must quit before the price reaches 9, as his expected value is lower than Bidder 1's. Hence, no aggregation of information is possible.

RESULT 7. In any equilibrium of the $C$ game, Bidder 1 leaves the auction when the price reaches $t_{1}$. Bidders 2 leaves at a price strictly lower than 9 and higher than 8, and Bidder 3 leaves as soon as Bidder 2 leaves.

The auction performs very poorly as Bidder 1 always wins at a price in $[8,9)$, which implies that both revenue and efficiency would be higher if Bidder 3 were excluded from the competition. We can 
say that, in this framework, Bidder 3 is a free rider whose presence is detrimental to both revenue and efficiency.

Now, let us consider the J game.

RESULT 8. An equilibrium of the J game exists in which Bidder 2 calls a price 10 at the beginning of the auction and no other bidder stays active at that price.

Bidder 2, by calling a price 10, prevents all the possible information aggregation. That way, she also prevents the free-rider problem. Eventually, Bidder 2 wins with probability 1 at price 10, which yields her an expected profit of $\frac{1}{2}$. That is better than in the $\mathrm{C}$ game where she never wins. Expected revenue goes up from $R^{C} \in[8 ; 9)$ in the $\mathrm{C}$ game to $R^{J}=10$ in the type of equilibrium of the $\mathrm{J}$ game that we mention. Similarly, the expected value of the winner increases from $\frac{19}{2}$ in the $\mathrm{C}$ game to $\frac{21}{2}$ in the $\mathrm{J}$ game.

The different environments that we have introduced allow us to conclude the section with the following result.

COROLLARY 2. Allowing bidders to call a price can decrease or increase revenue and efficiency depending on the considered setting.

Proof. We only need to provide examples where all these possibilities are covered. The settings in the previous subsections prove that revenue and efficiency can drop. The setting above proves that they can increase.

\section{Conclusion}

We have analysed a version of the Japanese auction that allows bidders to stop the continuous price increase and call a price at any point during the auction. We have looked at how the possibility to call a price affects the way information is aggregated and have shown that bidders may have an incentive to alter the aggregation of information by placing jump bids to hide the drop-out value of some of their opponents. This is a novel explanation to jump bidding that contrasts with the traditional one based on signaling, for which more rather than less information is available after a jump bid. The general wisdom that comes with the traditional approach is that jump bids are anticompetitive. We show instead that the strategic environment is so rich that this is not always the case. Our analysis shows that the possibility of placing jump bids strongly affects both revenue and efficiency.

Université Paris Dauphine, LEDa, CEREMADE, and CIRANO

CERGE-EI 


\section{Appendix A}

\section{Proof of Result 2}

Consider the following strategies:

- Bidder 1. If $t_{1} \leq p^{*}$, stay active until the auction reaches $t_{1}$, leave at that price and never calls a price. If $t_{1}>p^{*}$, stay active until the auction reaches $p_{1}=\frac{-4 \alpha+6 \alpha \beta+2 \beta t_{1}-\beta^{2} t_{1}}{4-8 \beta+5 \beta^{2}}$, call $p_{2}=\frac{4 \alpha(\beta-1)+\beta^{2} t_{1}}{4-8 \beta+5 \beta^{2}}$ at that price and then stay active up to $t_{1}$ without calling a price. If a jump bid $\left(\widehat{p}_{1}, \widehat{p}_{2}\right)$ is called such that $\widehat{p}_{1}<p_{1}$ and $p_{2} \in\left[p_{1}, \frac{4 \alpha(\beta-1)+\beta^{2} t_{1}}{4-8 \beta+5 \beta^{2}}\right]$, follow the jump bid and immediately call $\frac{4 \alpha(\beta-1)+\beta^{2} t_{1}}{4-8 \beta+5 \beta^{2}}$. If a jump bid $\left(\widehat{p}_{1}, \widehat{p}_{2}\right)$ is called such that $\widehat{p}_{1}<p_{1}$ and $p_{2}>\frac{4 \alpha(\beta-1)+\beta^{2} t_{1}}{4-8 \beta+5 \beta^{2}}$, follow the jump bid if and only if $\widehat{p}_{2}<t_{1}$ and stay active up to $t_{1}$ without calling a price.

- Bidder 2. Stay active until the auction reaches $t_{2}$, leave at that price or when a price higher than $t_{2}$ is called. Never call a price.

- Bidder 3. Never call a price. As long as no price is called, follow behaviour A : Stay active as long as Bidder 2 does also; if Bidder 2 leaves when the price is lower than $p^{*}$, immediately leave; if Bidder 2 leaves at a price $p>p^{*}$, stay active up to $\max \{\beta-\alpha, \beta p-\alpha\}$. If a jump bid $\left(p_{1}, p_{2}\right)$ with $p_{2} \leq 1$ is called by Bidder 1 , stay active. If Bidder 2 also stays active after the jump, follow behaviour A. If Bidder 2 does not follow the jump bid and $p_{2} \leq p^{*}$, immediately leave the auction; if Bidder 2 does not follow the jump bid and $p_{2}>p^{*}$, stay active up to $\max \left\{p_{2}, \beta \frac{\left(p_{1}+p_{2}\right.}{2}-\alpha\right\}$. If Bidder 2 was not active when the price was called and had left the auction at a price $p>p^{*}$, follow the jump bid if and only if $p_{2} \leq \beta p-\alpha$ and stay active up to $\beta p-\alpha$.

Considering Bidder 3's strategy, it is obvious that Bidder 2 cannot derive any profit whatever his strategy. Besides, the proposed strategy for Bidder 2 is the only non dominated strategy without jump bids.

Bidder 3 at any price $p$ stays active at least up to his expected value for the good conditional on the equilibrium information available at $p$. Leaving at a lower price could not raise his profit. As we mentioned when we considered the $C$ game, even though the wait and see strategy for value lower than $p^{*}$ may appear costly, it is eventually always profitable. Bidder 3 may also consider calling a price. This could only be profitable if it would deter Bidder 1 from calling a price, so that Bidder 3 could have access to finer information about Bidder 2's type. However, considering Bidder 1's strategy, no jump bid can deter Bidder 1 from calling price $\frac{4 \alpha(\beta-1)+\beta^{2} t_{1}}{4-8 \beta+5 \beta^{2}}$ (or this would require calling a price higher than $\left.\frac{4 \alpha(\beta-1)+\beta^{2} t_{1}}{4-8 \beta+5 \beta^{2}}\right)$. 
Now, let us consider Bidder 1. If $t_{1} \leq p^{*}$, she can only derive a profit if $t_{2}<t_{1} \leq p^{*}$. In that case, when Bidder 2 leaves the auction, Bidder 3 also leaves immediately. Then, calling a price is costly and cannot be profitable. Staying active up to her valuation is a best response to Bidder 2 and Bidder 3's strategies. If $t_{1}>p^{*}$, leaving the auction at a price strictly lower than her valuation is a dominated strategy. Is it possible to place a profitable jump bid?

Consider a jump bid $\left(p_{1}, p_{2}\right)$ with $p_{2} \leq p^{*}$. If Bidder 2 is still active after the jump bid, calling the price is costless but useless. If Bidder 2 does not stay active after the jump bid, Bidder 3 also immediately leaves. With the jump bid, Bidder 1 obtains the good and pays $p_{2}$; without the bid, she would also have won but she would have paid a strictly lower expected price for the good. Therefore a jump bid $\left(p_{1}, p_{2}\right)$ with $p_{2} \leq p^{*}$ cannot be part of a Bidder 1's best response.

Consider a jump bid $\left(p_{1}, p_{2}\right)$ with $p_{1} \geq p^{*}$. If Bidder 2 is still active after the jump bid, calling the price is costless but useless. If Bidder 2 does not stay active after the jump bid, Bidder 3 stays active up to $\beta \frac{p_{1}+p_{2}}{2}-\alpha\left(>p_{2}\right)$. If $t_{1}>\beta \frac{p_{1}+p_{2}}{2}-\alpha$, with the jump bid, Bidder 1 obtains the good and pays $\beta \frac{p_{1}+p_{2}}{2}-\alpha$, without the jump bid, she would also have won the good and she would have paid the same expected price. If $t_{1} \leq \beta \frac{p_{1}+p_{2}}{2}-\alpha$, she does not derive any profit after the jump bid, although she may have obtained a strictly positive profit without jump bid if $\beta p_{1}-\alpha<t_{1}$. Therefore a jump bid $\left(p_{1}, p_{2}\right)$ with $p_{1} \geq p^{*}$ cannot be part of a Bidder 1's best response.

Suppose now that Bidder 1 places a jump bid $\left(p_{1}, p_{2}\right)$ with $p_{1}<p^{*}<p_{2}<t_{1}$. Again, if Bidder 2 stays active after the jump bid, it is useless and costless. Suppose that Bidder 2 does not stay active after the jump bid, so that Bidder 1 stays active up to $\max \left(p_{2}, \beta \frac{p_{1}+p_{2}}{2}-\alpha\right)$ and this may be profitable if $\max \left(p_{2}, \beta \frac{p_{1}+p_{2}}{2}-\alpha\right)<E\left[\max \left(t_{2} ; \beta t_{2}-\alpha\right) \mid t_{2} \in\left[p_{1}, p_{2}\right]\right]$.

Therefore, a jump bid may be profitable, but what is the most profitable jump bid?

To find the optimal jump bid, first consider a jump bid $\left(p_{1}, p_{2}\right)$ with $p_{1}<p^{*}<p_{2}<t_{1}$ and such that $\beta \frac{p_{1}+p_{2}}{2}-\alpha<p_{2}$. Bidder 1 can obtain a higher revenue by placing a jump bid $\left(p_{1}^{\prime}, p_{2}\right)$ with $p_{1}^{\prime}>p_{1}$ such that $\beta \frac{p_{1}^{\prime}+p_{2}}{2}-\alpha=p_{2}$. As a matter of fact, the outcome is the same with both jump bids except when $t_{2} \in\left[p_{1}, p_{1}^{\prime}\right)$. In that case, with a jump bid $\left(p_{1}, p_{2}\right)$, Bidder 1 obtains the good and pays $p_{2}$ while with a jump bid $\left(p_{1}^{\prime}, p_{2}\right)$, she obtains the good and pays a price strictly lower than $p_{1}^{\prime}$ and therefore strictly lower than $p_{2}$. Therefore a jump bid $\left(p_{1}, p_{2}\right)$ with $\frac{\beta}{2}\left(p_{1}+p_{2}\right)-\alpha<p_{2}$ cannot be part of a best response for Bidder 1 .

Consider now a jump bid $\left(p_{1}, p_{2}\right)$ with $p_{1}<p^{*}<p_{2}<t_{1}$ and such that $\beta \frac{p_{1}+p_{2}}{2}-\alpha>p_{2}$. Bidder 1 can obtain a higher revenue by placing a jump bid $\left(p_{1}, p_{2}-\varepsilon\right)$ with $\varepsilon>0$ and arbitrarily small. If $t_{2} \in\left[p_{1}, p_{2}-\varepsilon\right]$, Bidder 1 obtains the good at a price $\beta \frac{p_{1}+p_{2}}{2}-\alpha$ with a jump bid $\left(p_{1}, p_{2}\right)$ while she obtains it at a price $\beta \frac{p_{1}+p_{2}}{2}-\alpha-\beta \frac{\varepsilon}{2}$ with a jump bid $\left(p_{1}, p_{2}-\varepsilon\right)$. If $t_{2} \in\left[p_{2}-\varepsilon, p_{2}\right]$, Bidder 1 obtains the good at a price $\beta \frac{p_{1}+p_{2}}{2}-\alpha$ with a jump bid $\left(p_{1}, p_{2}\right)$, while she obtains it at an expected price $\beta p_{2}-\frac{\beta \varepsilon}{2}-\alpha$ or does not even obtain the good (if $\beta p_{2}-\alpha>t_{1}$ ) with a jump bid $\left(p_{1}, p_{2}-\varepsilon\right)$. 
The expected revenue is therefore equal to $\left(p_{2}-p_{1}\right)\left(t_{1}-\left(\beta \frac{p_{1}+p_{2}}{2}-\alpha\right)\right)$ with a jump bid $\left(p_{1}, p_{2}\right)$ and it is equal to $\left(p_{2}-p_{1}-\varepsilon\right)\left(t_{1}-\left(\beta \frac{p_{1}+p_{2}}{2}-\alpha-\beta \frac{\varepsilon}{2}\right)\right)+\gamma$, with $\gamma \geq \varepsilon\left(t_{1}-\beta p_{2}+\beta \varepsilon^{2} / 2-\alpha\right)$. Since $\left(p_{2}-p_{1}-\varepsilon\right)\left(t_{1}-\left(\beta \frac{p_{1}+p_{2}}{2}-\alpha-\beta \frac{\varepsilon}{2}\right)\right)+\varepsilon\left(t_{1}-\beta p_{2}+\beta \varepsilon^{2} / 2-\alpha\right)=\left(p_{2}-p_{1}\right)\left(t_{1}-\left(\beta \frac{p_{1}+p_{2}}{2}-\alpha\right)\right)$, Bidder 1 either obtains the same expected revenue with the two jump bids or a strictly lower expected revenue with $\left(p_{1}, p_{2}\right)$ than with $\left(p_{1}, p_{2}-\varepsilon\right)$ (when $\left.\beta p_{2}-\alpha>t_{1}\right)$. Hence, we can restrict to jump bids $\left(p_{1}, p_{2}\right)$ with $p_{1}<p^{*}<p_{2}<t_{1}$ and such that $\beta \frac{p_{1}+p_{2}}{2}-\alpha=p_{2}$. In such a jump bid, $p_{2}=\frac{2 \alpha-\beta p_{1}}{\beta-2}$.

Considering Bidder 2 and Bidder 3's strategies, the expected revenue of Bidder 1 calling a price $\left(p_{1} ; \frac{2 \alpha-\beta p_{1}}{\beta-2}\right)$ with $p_{1}<p^{*}<t_{1}$ is

$$
\begin{aligned}
p_{1}\left(t_{1}-p_{1} / 2\right)+\left(\frac{2 \alpha-\beta p_{1}}{\beta-2}-p_{1}\right)\left(t_{1}-\left(\frac{2 \alpha-\beta p_{1}}{\beta-2}\right)\right)+ & \\
& \left(\frac{t_{1}+\alpha}{\beta}-\frac{2 \alpha-\beta p_{1}}{\beta-2}\right)\left(t_{1}-\beta \frac{2 \alpha-\beta p_{1}}{\beta-2}-\alpha\right) / 2 \mathbb{1}_{t_{1} \geq \frac{2 \alpha-\beta p_{1}}{\beta-2}}
\end{aligned}
$$

With simple computations, we show that it is maximized in $p_{1}=\frac{-4 \alpha+6 \alpha \beta+2 \beta t_{1}-\beta^{2} t_{1}}{4-8 \beta+5 \beta^{2}}$, which implies $p_{2}=\frac{4 \alpha(\beta-1)+\beta^{2} t_{1}}{4-8 \beta+5 \beta^{2}}$.

Q.E.D. 


\section{References}

Avery, C. (1998): "Strategic Jump Bidding in English Auctions," The Review of Economic Studies, $65,185-210$.

Bernhardt, D., and D. Scoones (1993): "Promotion, Turnover and Preemptive Wage Offers," American Economic Review, 83, 771-791.

Betton, S., And B. Eckbo (2000): "Toeholds, bid jumps, and expected payoffs in takeovers," Review of Financial Studies, 13(4), 841-882.

Bhattacharyya (1992): "The Analytics of Takeover Bidding: Initial Bids and their Premia," working paper.

Börgers, T., And C. Dustmann (2005): "Strange Bids: Bidding Behaviour in the United Kingdom's Third Generation Spectrum Auction," The Economic Journal, 115(505), 551-578.

Bulow, J., And P. Klemperer (2009): "Why Do Sellers (Usually) Prefer Auctions?," American Economic Review, 99(4), 1544-75.

Burkart, M., And F. PANunzi (2008): "Takeovers," in Handbook of European Financial Markets and Institutions, ed. by P. H. Freixas, X., and C. M. (eds.), pp. 265-297. Oxford University Press.

Compte, O., and P. Jehiel (2004): "The Wait and See Option in Ascending Price Auctions," Journal of the European Economic Association, 2(2), 494-503.

- (2007): "Auction and Information Acquisition: Sealed Bid or Dynamic Formats," The RAND Journal of Economics, 38(2), 355-372.

Cramton, P. (1997): "The FCC spectrum auctions: An early assessment," Journal of Economics and Management Strategy, 6(3), 431-495.

Dimopoulos, T., And S. Sacchetto (2013): "Preemptive Bidding, Target Resistance, and Takeover Premiums," Swiss Finance Institute Research Paper Series 11-47, http://ssrn.com/abstract $=1945837$.

Easley, R. F., and R. Tenorio (2004): "Jump Bidding Strategies in Internet Auctions," Management Science, 50(10), 1407-1419.

Ettinger, D., and F. Michelucci (2012): "Hiding Information in Open Auctions," CERGE-EI WP 469, https://www.cerge-ei.cz/pdf/wp/Wp469.pdf.

Fishman, M. J. (1988): "A Theory of Preemptive Takeover Bidding," The RAND Journal of Economics, 19, 88-101. 
Grether, D., D. Porter, And M. Shum (2012): "A Field Experiment of Jump Bidding in Online Automobile Auctions," Caltech, Mimeo, http://www.hss.caltech.edu/ mshum/papers/jump.pdf.

He, Y., and P. Popkowski Leszczyc (2013): "The impact of jump bidding in online auctions," Marketing Letters, pp. 1-11.

Hernando-Veciana, A., and F. Michelucci (2011): "Second Best Efficiency and the English Auction," Games and Economic Behavior, 73(2), 496-506.

(2013): "Do Not Panic: How to Avoid Inefficient Rushes Using Multi-Stage Auctions," CERGE-EI Working Paper series, 489, http://www.cerge-ei.cz/pdf/wp/Wp489.pdf.

Hirshleifer, D., And I. P. L. PNG (1989): "Facilitation of Competing Bids and the Price of a Takeover Target," The Review of Financial Studies, 2-4, 587-606.

Hörner, J., And N. Sahuguet (2007): "Costly Signalling in Auctions," The Review of Economic Studies, 74(1), 173-206.

Kirkegaard, R. (2006): "The Phantom Made Me Jump! Preemptive Jump Bidding in (Takeover) Auctions," Brock University, mimeo, http://www.uoguelph.ca/ rkirkega/PhantomJump.pdf.

Mark, I. R., T. C. Salmon, and A. Zillante (2007): "A theory of jump bidding in ascending auctions," Journal of Economic Behavior and Organization., 62(1), 144-164.

Plott, C. R., and T. C. Salmon (2004): "The simultaneous, ascending auction: dynamics of price adjustment in experiments and in the $\{\mathrm{UK} 3 \mathrm{G}\}$ spectrum auction," Journal of Economic Behavior and Organization, 53(3), $353-383$.

Roberts, J. W., And A. Sweeting (2013): "When Should Sellers Use Auctions?," American Economic Review, 103(5), 1830-61. 